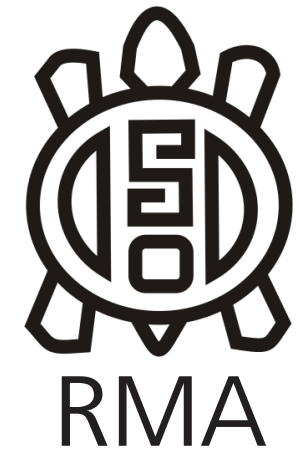

Antropología Social

\title{
Hacia una visceralidad atmosférica
}

\section{Renzo Taddei. Meteorologistas e profetas da chuva. Conhecimentos, práticas e políticas da atmosfera. 2017. San Pablo: Terceiro Nome.}

Mariano Bussi

Instituto de Antropología de Córdoba (IDACOR, CONICET-UNC)

marianobussi@gmail.com

En la región semiárida del nordeste brasileño, llamada Sertón (sertão), viaja un pequeño grupo de meteorólogos. Piden permiso en la casa de un anciano para pasar la noche. Él los acepta y les ofrece pasar adentro para no mojarse con la lluvia que caerá, asegura, esa misma noche. Los científicos se ríen del campesino y le dicen que no lloverá, que lo saben por ser ese su arte y ciencia, y que con unas hamacas colgantes estarán más que cómodos para pasar la noche. Sin problemas, el anciano sertanejo les entrega lo que buscan. Horas más tardes, ya en medio de la oscuridad y el chaparrón, los citadinos vuelven a la puerta para pedir por favor pasar a dormir adentro, a refugiarse de la lluvia. Por la mañana siguiente, le preguntan al hombre cómo ha sabido tan claramente que llovería. Él les responde que aquel burro viejo de una sola oreja, aquel que está al frente de la casa, se estaba guareciendo bajo un árbol: sabiendo que llovería, evitaba así que el agua le entre por su oído a la intemperie. Lección: mejor un burro meteorólogo que un meteorólogo burro.

¿Qué herramientas técnicas y conceptuales utilizan los meteorólogos para pronosticar el tiempo? ¿Qué diferencias tienen éstas con las propias de aquellos campesinos sertanejos, profetas de la lluvia? ¿Cuáles son las condiciones sociales, culturales, ontológicas de posibilidad que sugieren estas diferencias? A su vez, y entendiendo que en estas diferencias también habita el ejercicio del poder, ¿cómo se vincula cada colectivo con el otro? ¿Cómo se construye y comunica el conocimiento en cada caso? Este relato nos abre a las preguntas centrales del libro Meteorologistas $e$ profetas da chuva. Conhecimentos, práticas e políticas da atmosfera, de Renzo Taddei. Reuniendo una serie de textos propios ya publicados entre 2006 y 2014, este libro expresa la evolución del trabajo antropológico de Taddei, profundamente atravesado por su experiencia etnográfica en el Sertón.
Meteorologistas e profetas da chuva... está compuesto por diez capítulos, divididos en dos partes: "Fuerza" y "Flujo". En cada capítulo la atmósfera es la protagonista. No es un fondo sobre el cual la vida social acontece, ni una excusa para tratar los temas a los que estamos acostumbrados: el poder, la estrategia social, la identidad. Aquí, la atmósfera es una relación compuesta por acciones. La atmósfera hace cosas y es también hecha a fuerza de otras relaciones. En el relato, la lluvia concede la razón a las técnicas del profeta antes que a las del meteorólogo. Poca importancia hubiese tenido la lluvia si los científicos hubiesen dudado de su conocimiento, confiado en el campesino o simplemente aceptado la propuesta del anciano.

A lo largo de la primera parte del libro Taddei nos muestra progresivamente la complejidad que vincula los conocimientos científicos con los tradicionales bajo el signo de un "colonialismo epistemológico". El discurso científico, los medios de comunicación y la política estatal son campos en los que funcionan mecanismos que aseguran la supremacía de un conocimiento por sobre el otro. Nuestro autor propone un análisis en el cual acusa la construcción de una "climatización de la pobreza" que busca responsabilizar por la situación social a la sequía estructural de la región antes que a las políticas estatales pertinentes. Además, en este colonialismo epistemológico los conocimientos atmosféricos campesinos son "folclorizados": se les quita potencia y se los presenta mediáticamente como un elemento más de la identidad regional que el turista puede consumir.

A mi entender, "Flujo", la segunda parte del libro, ensaya deshacer ese embrujo al llevar a un primer plano, de manera novedosa y potente, los modos campesinos de construir saberes. El anciano del relato sabe que lloverá al observar al burro, sus formas, su conducta, 
sus particularidades, su vínculo con el ambiente. Es esa "interpelación entre los cuerpos" dada en un medio preciso lo que fundamenta y hace existir el conocimiento de los profetas de la lluvia. Taddei sostiene y sustenta la "visceralidad" de este pensar, su origen en las entrañas, en la materialidad de los cuerpos. En esta clave, el autor propone una vía "terapéutica" para el trabajo antropológico: que la reflexión basada en las experiencias vitales de las personas con las que se investiga sea una herramienta posible para transformar esferas de nuestro propio universo conceptual y existencial.

Podrá objetarse que este movimiento no nesecesariamente original: el mismo Taddei nos remonta hacia otros textos y otros autores. Sin embargo, es en su anclaje atmosférico cuando esta propuesta cobra su singular valor. En el artículo que cierra el libro, Taddei nos acerca al concepto de "alter geoingeniería", con el que comprende el desarrollo de tecnologías que afecten los sistemas climáticos (Ilamadas geoingeniería) partiendo de vidas, conocimientos y mundos otros, no hegemónicos en eso que llamamos Occidente. Aquí, volvemos sobre la pregunta: ¿en qué se fundamentan las prácticas y los conocimientos que construimos en torno a lo atmosférico? Cuando la atmósfera nos pone de frente con los efectos del desarrollo, el capitalismo y la ciencia que supimos nefastamente concebir, estos interrogantes se tornan imprescindibles.

La Fundación Cacique Cobra Coral es la protagonista del último trabajo etnográfico de Taddei: esta organización ofrece servicios de intervención en las dinámicas atmosféricas a través de las capacidades del espíritu del jefe indígena norteamericano (masculino) que le da nombre. El servicio de esta agrupación (gratuito para entidades estatales brasileñas y pago para empresas privadas) se realiza a través de un cuerpo humano femenino dentro de un marco institucional que responda a las exigencias de los solicitantes, como la de asegurar un cielo sin lluvias durante un festival internacional de música. Este cuerpo agencia las fuerzas de aquel espíritu orientándolas según las recomendaciones obtenidas de meteorólogos profesionales, para asegurar que se cumplan los objetivos de las organizaciones contratantes. Nubes, espiritismo, ciencia atmosférica, cuerpos, entidades estatales y privadas, personalidades públicas, corrientes de viento y otros agentes forman parte de este universo que conspira a favor de quienes adecuadamente lo soliciten.

Renzo Taddei cierra su libro apostando por la necesidad de llevar a un primer plano del pensamiento las formas indígenas, campesinas y espiritistas de hacer lo atmosférico. Todas vías alternas -aunque no necesariamente excluyentes- al conocimiento científico contemporáneo, todas vías minorizadas por este. Meteorologistas e profetas da chuva... funciona como una interpelación, una invitación inesperada a afrontar antropológicamente la mala hora de nuestro mundo.

Córdoba, 21 de marzo de 2019 